\title{
INFÂNCIA E EXPERIÊNCIAS EDUCATIVAS NO EDUCANDÁRIO EUNICE WEAVER EM BELÉM/PARÁ (1942-1980)
}

Tatiana do Socorro Corrêa Pacheco ${ }^{1}$

\section{INTRODUÇÃO}

Este artigo apresenta alguns resultados da pesquisa realizada no doutorado em educação (UFPA//2017) que teve a finalidade de explicitar a infância e as experiências educativas de crianças que foram internas no Educandário Eunice Weaver em Belém do Pará no período de 1942-1980. O Educandário Eunice Weaver foi criado para atender uma política pública sanitarista compulsória implantada no Brasil na primeira metade do século XX que preconizava o isolamento de hansenianos e de seus filhos saudáveis para o controle e prevenção da hanseníase.

No Pará, a prática de isolamento em asilos e hospitais de pessoas com doenças infectocontagiosas, era adotada desde o século XIX, e a forte presença e influência de médicos na política e no exercício de cargos públicos no início do século XX, favorecia e reforçava esse tipo de ação para o controle de endemias como a hanseníase, para proteção e higiene da população e limpeza da cidade. A internação de crianças em instituições, também era uma prática bastante presente no Estado, e as dificuldades em combater doenças que naquele momento eram consideradas como incuráveis tinha no isolamento o seu principal recurso. Foi num contexto cultural constituído pela prática de internamento de doentes e crianças em instituições de isolamento que o Educandário Eunice Weaver foi criado.

A singularidade do grupo que frequentou a instituição os tornou atores centrais nesse processo de isolamento, nos direcionando para um estudo histórico em que a preocupação e foco não está apenas, em estudar as práticas e diretrizes registradas nos documentos oficiais da instituição, mas também, na tentativa de apreender e registrar as experiências dos sujeitos que ali vivenciaram as suas infâncias. Gouvea (2009) enfatiza a importância do recurso à história oral na produção da história da infância, enfatizando que a utilização da história oral, “[...] produz um relato mais vivo dos processos

\footnotetext{
${ }^{1}$ Doutora em Educação pelo Programa de Pós-Graduação em Educação da UFPA. Professora Adjunta da Universidade Federal Rural da Amazônia/UFRA-PA. Email: tatianacpacheco@gmail.com
} 
históricos de socialização, bem como dos espaços de inserção das crianças a partir do olhar dos sujeitos que o experimentaram [...]" (p.114).

Para obtenção do objetivo proposto utilizamos como procedimentos a pesquisa documental e a história oral híbrida e temática, pois, nesse tipo de procedimento, valoriza-se o tema pesquisado, e, os dados orais entram em diálogo com outras fontes, que podem ser os documentos e os referenciais de análise. Foi realizada entrevista semi-estruturada com 13 ex-internos, com idades entre 44 e 77 anos. Foram atribuídos nomes fictícios aos participantes da pesquisa, para preservar as identidades destes.

Autores como Michel Foucault nos deram aporte para as análises empreendidas. Autores do campo da história da infância e dos estudos da criança numa perspectiva sociológica, histórica e cultural, como Rizzini e Sarmento, também contribuíram com as análises. Os registros escritos foram encontrados na biblioteca virtual do Centro de Pesquisa e Documentação de História Contemporânea do Brasil - CPDOC, da Fundação Getúlio Vargas/RJ, no Arquivo Público do Pará e no setor de obras raras da biblioteca Arthur Viana/CENTUR, em Belém/PA.

\section{A LEPRA É DOENÇA DA INFÂNCIA: OS DISCURSOS MÉDICOS E SOCIAIS QUE JUSTIFICARẢM O ISOLAMENTO DAS CRIANÇAS E A CONSTRUÇÃO DO EDUCANDÁRIO EM BELÉM.}

A infância, como instância de controle do Estado, teve as suas primeiras políticas sociais no Brasil a partir da década de 1930. Nesse processo de reconhecimento da função social da infância e das especificidades das crianças, foram sendo criados espaços específicos para esses sujeitos. A área médica, segundo Rizzini (2008), era a mais efetiva nas orientações e prescrições para a infância. Um dos focos pontuais da atuação médica estava voltada para o controle das doenças, pois esta era uma condição precípua na missão salvacionista do país. Acreditava-se que o controle das doenças, também se dava por meio do controle das crianças, por isso as medidas prescritivas de cuidados com a higiene e alimentação das crianças.

A ideologia higienista visava a proteção do meio ambiente e do indivíduo. Os discursos de combate às impurezas do corpo, de limpeza das cidades, de limpeza da infância, entrelaçavam-se em uma única ideia - a de limpeza. E a doença, uma sujeira do corpo, que poderia se alastrar pelo espaço público, contribuindo para a contaminação e sujeira das cidades, era uma ameaça que deveria ser combatida. Pois, muitas doenças ameaçavam o desenvolvimento das cidades em que a sua higienização, tinha como foco, retirar do espaço público tudo que poderia impedir o seu 
melhoramento, a sua limpeza. E a hanseníase era uma doença que historicamente carregou o medo, o preconceito e as incertezas em seu tratamento, o que conduziria ao isolamento compulsório dos doentes, e das crianças, filhas de doentes, na década de 1930.

Os discursos médicos e sociais, de proteção à infância e defesa da raça e da sociedade, reforçavam a necessidade do isolamento institucional da criança para que pudessem ficar protegidas do contágio da doença. Por isso, o isolamento de crianças encontrou força, eco, e justificavas para a sua implantação, pois “[...] a missão "saneadora” do país, no que tange a infância, era elaborada como parte do projeto de construção nacional, desde os primeiros anos de instauração do regime republicano [...]” (RIZZINI, 2008, p.77).

Em Belém, a medicina acompanhava os avanços e práticas empreendidas pelos grandes centros urbanos do país, como o Rio de Janeiro. Silva (2014) ao analisar a institucionalização da medicina acadêmica em Belém, no final do século XIX e início do século XX, constatou que, o processo de institucionalização da medicina acadêmica do Rio de Janeiro serviu de referência para quase todo o país. Esse autor também informa que, muitos médicos higienistas em Belém receberam formação na Faculdade de Medicina do Rio de Janeiro e ocuparam cargos públicos importantes no campo da saúde pública do Estado do Pará ${ }^{2}$. Portanto, os médicos paraenses estavam envolvidos nos debates sobre doenças, epidemias, pesquisa experimental e, as descobertas no campo da biologia.

O isolamento como medida profilática das pessoas com hanseníase foi defendido por médicos como Oswaldo Cruz, Heraclides C. de Souza Araújo e Belisário Penna. Belisário Penna em Conferência realizada na Academia Nacional de Medicina em 1926, apontava a hanseníase como o mais grave problema sanitário do Brasil, destacando a infância e a imigração como fatores de proliferação da doença.

Os estudos que Souza-Araujo e Jaime Aben Athar, realizaram no Pará, sobre a incidência dos casos de hanseníase e a idade de manifestação da doença, eram utilizados por Belisário Penna, para reforçar em seus discursos os perigos da doença na infância e a necessidade de isolamento das crianças dos pais infectados. O médico defendia que as medidas profiláticas deveriam ser pautadas na segregação dos doentes, na vigilância e exames periódicos dos comunicantes e no afastamento dos filhos saudáveis de seus pais, para serem criados em ambiente limpo. “[...] O afastamento das

\footnotetext{
2 Destaco o médico paraense Jaime Aben Athar, pelos estudos que realizou sobre a hanseníase no Pará. Este médico seguidor da medicina pasteuriana, foi membro do Instituto de Manguinhos no Rio de Janeiro, que foi dirigido por Oswaldo Cruz (Silva, 2014).
} 
crianças, logo após o nascimento, salva-as do flagelo, e quebra um dos elos da cadeia da endemicidade leprosa [...]" (PENNA, 1926, p.25).

Os efeitos de verdade que esses discursos produziram sobre a sociedade, permitiu o isolamento institucional de crianças sadias por mais de 04 décadas em todo Brasil. Nos termos foucaultianos uma medicina de exclusão, de exílio, com um regime de verdade que produziu efeitos regulamentadores de poder, um tipo de discurso que foi escolhido pela sociedade por meio de seus representantes legais, como médicos, filantropos e políticos, que em uma rede de acordos, práticas e funções, exerceram o poder com base no que foi instituído, sócio culturalmente, como verdadeiro sobre o tratamento da doença.

O médico paraense, Jaime Aben-Athar ${ }^{3}$, possuía notoriedade nacional nos estudos que desenvolvia sobre a hanseníase no Estado do Pará. A afirmação em seus estudos de que o contágio da doença se dava principalmente na infância, reforçava a proposta de isolamento das crianças saudáveis em instituições. No documento lançado para a campanha de criação do preventório em Belém $^{4}$, os discursos que justificavam a necessidade de criação deste espaço tinham como base as explicações de que a hanseníase, particularmente no Pará, era mais frequente nas crianças, por serem estas, mais suscetíveis ao contágio, por isso, deveriam ser retiradas do contato e convívio com o meio infectante.

Os discursos médicos desse período colocavam a hanseníase como doença da infância, fortalecendo e justificando dessa forma a implantação do isolamento institucional. Com a finalidade de acolher as crianças que não tinham hanseníase, foi criado na década de 1940, o Educandário Eunice Weaver em Belém espaço que foi construído com o empenho conjunto de médicos, de representantes da elite paraense, de representantes da classe média, de políticos e instituições filantrópicas e religiosas.

\section{A INFÂNCIA E O COTIDIANO DAS CRIANÇAS NO FUNCIONAMENTO DO EDUCANDÁRIO EUNICE WEAVER.}

Nos foi possível reconstituir o cotidiano das crianças, apreender as suas vivências no espaço institucional, as relações que eram permitidas, as brincadeiras, as atividades rotineiras, as sanções

\footnotetext{
3 Jayme Aben-Athar era professor da Faculdade de Medicina do Pará, diretor do Instituto de Higiene do Pará, chefe do serviço de profilaxia rural e foi membro do conselho técnico da Liga Contra a Lepra do Pará.

4 Documento intitulado: Campanha da solidariedade Em prol da construção do preventório para filhos sadios dos lázaros no Pará, de 1939.
} 
instituídas. Nessa rotina diária composta por diferentes atividades, uma das lembranças que emergiram e apareceram de forma latente nas narrativas que se seguiram, e que constituíram o cotidiano das crianças, foi o trabalho. As narrativas indicaram uma rotina e um cotidiano permeado pelo trabalho.

Destacamos as referências que os ex-internos fizeram ao trabalho como atividade prioritária no Educandário. Nas narrativas sobre o cotidiano institucional, o trabalho na infância aparece como um mecanismo de garantia da manutenção e funcionamento do espaço do institucional.

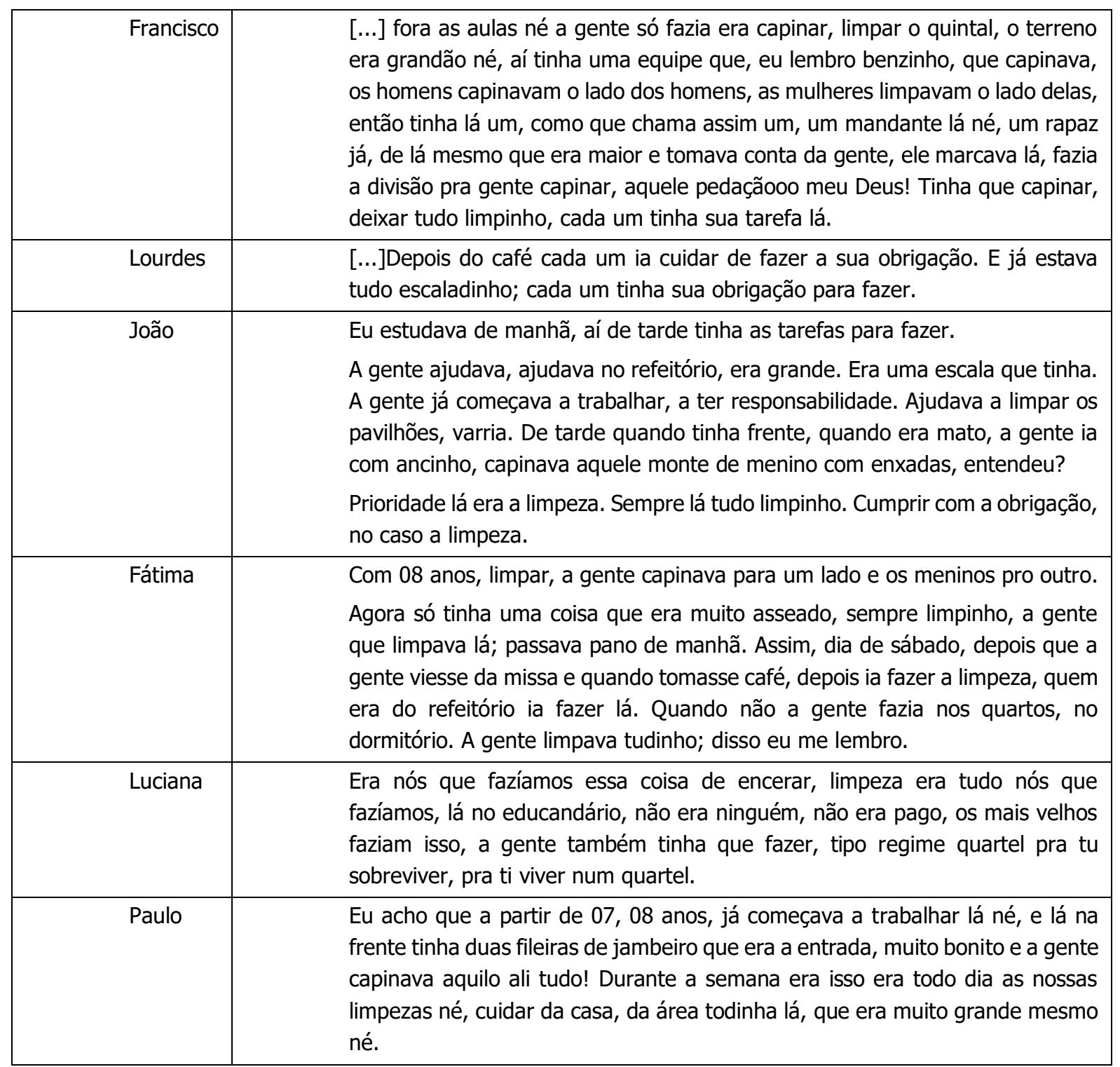


As narrativas indicam que havia uma divisão de tarefas que distribuía as crianças em todos os espaços da instituição. Os dormitórios, o refeitório, a área externa, são espaços mencionados nas narrativas em que eram realizadas limpeza pelas crianças, com a supervisão dos adultos.

O trabalho na infância possui uma relação histórica com a preocupação com o ócio, com o emprego de uma rotina para as crianças, em função dos perigos representados pelo "tempo livre". Trabalho e obediência sempre estiveram presentes na história da infância ocidental e de muitas crianças brasileiras, evidenciando a complexidade do ser criança que sempre esteve relacionada com os valores, as condições de organização econômica, política e social de determinada cultura.

Stearns (2006), ao fazer referência à presença do trabalho na história da infância destaca que a substituição das sociedades de caça e coleta pelas sociedades voltadas para o cultivo agrícola, trouxeram mudanças para a infância, com a inserção do trabalho produtivo e da utilidade das crianças nesse tipo de atividade, as crianças passaram a ser percebidas como força de trabalho e como contribuidoras da economia doméstica (STEARNS, 2006). O trabalho realizado pelas crianças não era questionado e as crianças trabalhadoras eram vistas como membros importantes na divisão de tarefas domésticas.

Para Heywood (2004), o trabalho nas sociedades agrícolas atribuiu uma nova importância à infância, pois as crianças passaram a ter um papel valorativo no meio familiar, em função da colaboração com a sua força de trabalho na economia familiar e no trabalho doméstico. Importância também atribuída nas sociedades industriais, uma vez que estas serviam como mão de obra nas fábricas, “[...] a fase inicial da industrialização dos séculos XVIII e XIX provocou uma dependência cada vez maior do trabalho infantil [...]" (HEYWOOD, 2004, P.173). Para esse autor, o setor manufatureiro era aquele que mais importância atribuía ao trabalho infantil, o processo de industrialização utilizou-se da mão de obra barata de crianças nas fábricas, e foi acompanhado pelo início de um período de implementação de leis regulamentadoras para esse tipo de atividade e, também, do incentivo a escolarização.

Tanto os estudos de Heywood quanto os de Stearns, destacam que as mudanças, nos conceitos e experiências na infância, possuem relação com as mudanças nos modelos econômicos das sociedades, nas suas formas de organização social. O modelo moderno de infância, trouxe a escolarização para o centro das finalidades da infância, “[...] envolve a passagem da infância, até então voltada ao trabalho, para a escolaridade [...] (STEARNS, 2006, p.90). 
A preocupação com a criança e com sua educação nas sociedades modernas, questionou o trabalho na infância. A compreensão e valorização da infância como uma etapa de preparação para a vida adulta, trouxe à realidade das sociedades industriais mais um paradoxo para as multiplicidades de infâncias: o trabalho de crianças como um meio de ajuda no sustento das famílias e a negação do trabalho nessa etapa da vida, em função da necessidade de educação escolar, e da compreensão da educação como um investimento no futuro, "[...] isso deu lugar à noção de que crianças pequenas não deveriam trabalhar de forma alguma, e em vez disso, ir para a escola [...]” (STEARNS, 2006, p.91). O "modelo de infância idealizado" nas sociedades modernas colocou a escola como o espaço apropriado para as crianças, o local autorizado social e culturalmente para a infância. A separação entre a infância e a vida adulta, distanciou as crianças do trabalho que passou a ser visto como função de adulto.

Acompanhando esse olhar voltado ao futuro, as crianças foram cada vez mais sendo segregadas em espaços destinados à sua educação e amparo. No entanto, nas instituições de internamento no Brasil, o trabalho de crianças era uma realidade e se articulava com as atividades de educação escolar, chegando a ser mais importante e prioritário do que a formação intelectual, como pudemos verificar em algumas narrativas que enfatizam o trabalho como atividade prioritária na instituição.

O Educandário, como instituição de amparo à infância, tinha no trabalho uma ação autorizada e legal. Os artigos 28 e 29 do regulamento dos preventórios fazem referências ao trabalho desenvolvido pelos internos na instituição:

Art.28 - Os internados maiores de 12 anos prestarão pequenos serviços ao Preventório, a título de aprendizagem, uma vez julgados aptos a faze-lo, sendo aproveitado o pendor natural que manifestarem por esta ou aquela atividade.

Art. 29 - Os internados maiores de 16 anos que prestarem eficientes serviços ao Preventório receberão uma gratificação nunca inferior a 30\% do salário que era pago por trabalho idêntico a empregado extranho.

$\S$ único - Metade dessa gratificação será entregue ao internado e a outra metade depositada na Caixa Econômica Federal ou no Banco do Brasil, em seu próprio nome, para lhe ser entregue quando atingir a maioridade.

O regulamento dos preventórios acompanhava o que era determinado pelo código de menores de 1927. No capítulo IX, do referido código, que trata do trabalho de menores, o art.101 proibia em 
todo o território nacional o trabalho antes dos 12 anos de idade. Porém, segundo algumas narrativas, o trabalho iniciava antes dos 12 anos de idade e não era exercido com a finalidade de aprendizagem ou como forma de preparação ou treinamento para o desenvolvimento de atividades na vida adulta ou como forma de desenvolver habilidades para determinada atividade, conforme indicava o regimento. Nas memórias destacadas o trabalho aparece como uma obrigação diária, com a finalidade de manter a limpeza do espaço institucional. As crianças eram usadas como fonte de trabalho e como meio de resolução dos problemas com pessoal para a manutenção da limpeza, sem objetivos de capacitá-las para a vida adulta.

O trabalho no Educandário configurava-se como um dever, o cotidiano das crianças era orientado por uma rotina de trabalho doméstico cansativo, conforme as narrativas apresentadas. As atividades de limpeza presentes nas narrativas, também indicam uma ênfase na higiene do espaço institucional. $\mathrm{O}$ foco na prevenção de doenças e na manutenção da saúde das crianças colocavam a higiene como atividade central para o bom funcionamento institucional.

O trabalho como mecanismo disciplinador e como estratégia para resolver os problemas com as despesas de manutenção do espaço predominava, em detrimento de seu uso como aprendizagem. O trabalho era utilizado como mecanismo de controle das crianças e como garantia da limpeza do espaço, já que as boas condições de higiene do local era mantida pelo trabalho das crianças. As exigências históricas da época dotavam o trabalho como instrumento de regeneração e correção por meio de uma rotina rígida de trabalho, de limpeza e higiene.

O trabalho apresentava-se como uma condição às crianças que viviam em instituições no Brasil. A centralidade no ideário de formação de futuros cidadãos úteis, tornava permissivo, apropriado e inquestionável o uso da mão-de-obra de crianças no trabalho institucional, apoiando-se na compreensão ideológica de que o trabalho recupera, regenera, forma, humaniza. Discurso que era reforçado pela educação cristã que ensinava as crianças a assumirem responsabilidades desde cedo. $\mathrm{O}$ ócio e a indisciplina eram combatidos com a rotina de trabalho implantada no cotidiano e funcionamento institucional.

Controle dos corpos pelo trabalho, promoção da disciplina pelo trabalho. A dimensão disciplinadora pelo trabalho fica evidenciada nas narrativas, o trabalho foi uma experiência na infância do Educandário mais presente e determinante nesse grupo de crianças do que a experiência do brincar e estudar. 
A imagem abaixo, retrata um espaço amplo, com uma fachada monumental, simbolizando o poder e a suntuosidade que representou o Educandário Eunice Weaver e seus idealizadores. Com uma estrutura arquitetônica com evidentes barreiras físicas de acesso e contato com o mundo externo, a edificação desse espaço seguia um modelo arquitetônico que primava pela vigilância e controle dos corpos. O Educandário Eunice Weaver, em Belém/PA, foi construído num espaço de extensão grandiosa, com uma área com $400 \mathrm{~m}$ de frente e $5.000 \mathrm{~m}$ de fundo ${ }^{5}$, ou seja, uma área de 200 hectares de terra, que permitiu a construção de um local autorizado legal e, culturalmente, para isolar crianças que não possuíam hanseníase.

\section{IMAGEM: ENTRADA PRINCIPAL DO EDUCANDÁRIO EUNICE WEAVER EM BELÉM}

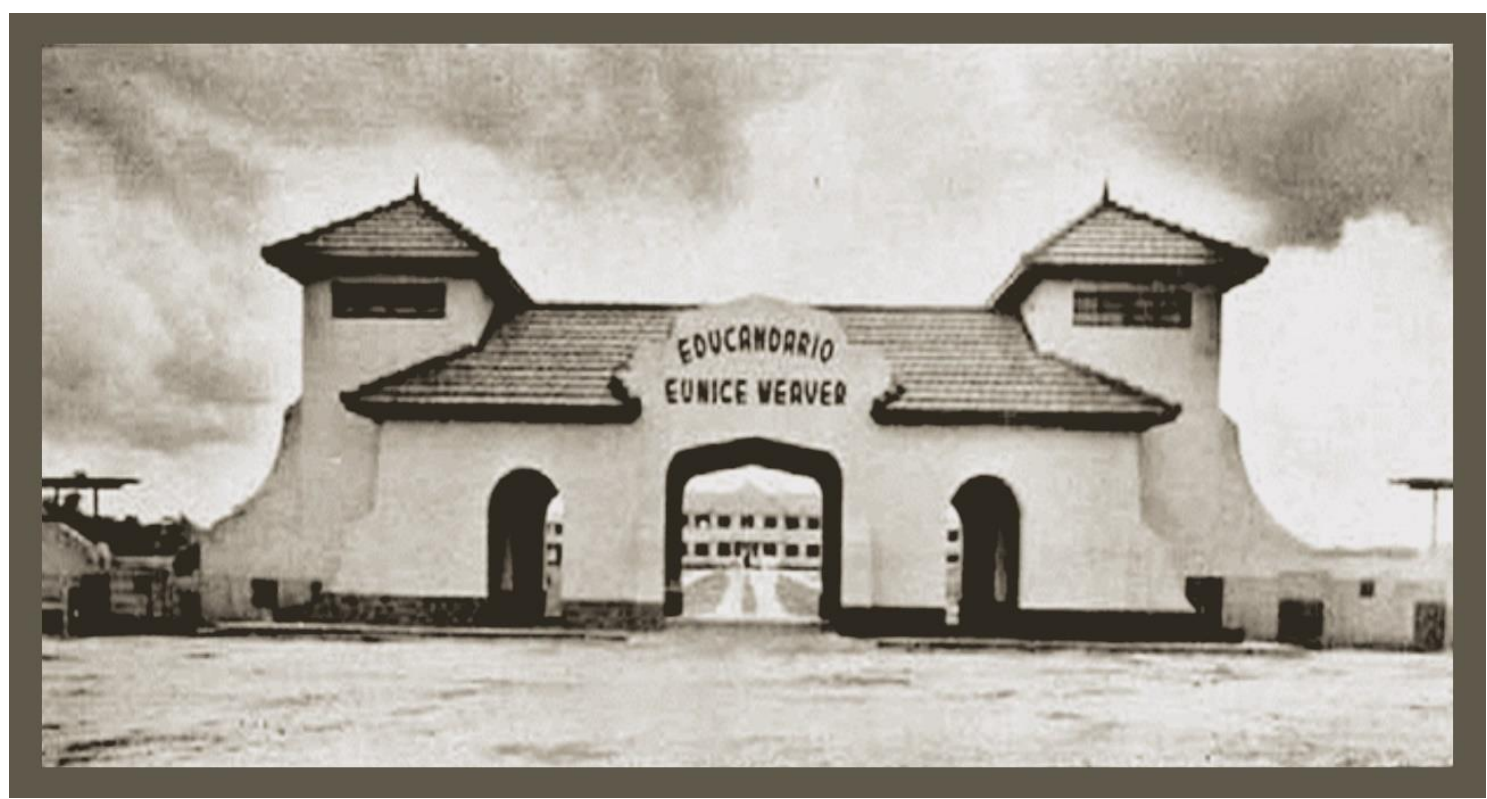

FONTE: HISTÓRIA DA LEPRA NO BRASIL. VOL. 2. ÁLBUM DAS ORGANIZAÇÕES ANTILEPROSAS. PERÍODO REPUBLICANO (1889-1946). RIO DE JANEIRO, IMPRENSA NACIONAL, 1948.

Nas narrativas dos ex-internos, também podemos conhecer as técnicas de disciplinamento acionadas para educar o corpo infantil. No quadro abaixo destacamos das narrativas de infância a presença marcante da disciplina, do controle e da vigilância dos corpos infantis.

\begin{tabular}{|l|l|}
\hline Margareth & $\begin{array}{l}\text { A gente apanhava, pegava castigo. Eram os funcionários, era homem e mulher que batia } \\
\text { na gente, vigiavam a gente, e como! }\end{array}$ \\
\hline Augusto & $\begin{array}{l}\text { Tem o lado ruim que quando a gente voltava os inspetores tratavam muito mal a gente } \\
\text { né! Ou eram pancadas, ou eram agressões verbais, ou era castigo... }\end{array}$ \\
\hline
\end{tabular}

\footnotetext{
${ }^{5}$ Revista da semana 23 de novembro de 1940
} 


\begin{tabular}{|c|c|}
\hline & $\begin{array}{l}\text { Ficar preso numa sala escura, tinha morcegos que frequentavam por lá e eles trancavam } \\
\text { a gente num salão, bem uns } 10 \text { que não se comportavam, que eles diziam que não se } \\
\text { comportavam, pra meter medo pra gente. }\end{array}$ \\
\hline Luciana & $\begin{array}{l}\text { [...] se caso a gente não passasse tinha o direito de ficar de castigo, chegamos a ficar de } \\
\text { castigo em cima de milho, na sala no escuro, apanhávamos de palmatória, essas coisa } \\
\text { tudo. }\end{array}$ \\
\hline Fátima & $\begin{array}{l}\text { Nesse tempo eu me lembro que eu apanhei de palmatória e muito! Porque a gente não } \\
\text { queria estudar, eles davam de palmatória nas pernas, aqui na batata da perna e não } \\
\text { podia mostrar. [...] Mas a gente penou muito no Educandário, eu me lembro que a gente } \\
\text { mijava na calça, davam na gente, davam, davam palmada nesse tempo. A gente fazia xixi } \\
\text { na calça quando dormia à noite, eles botavam assim, tipo uma flanela pra não varar pro } \\
\text { colchão. Ah, mas eu tinha um medo de manhã quando eu acordava que eu estava mijada, } \\
\text { porque eu sabia que a gente ia apanhar nas pernas, na bunda, eu me lembro benzinho. }\end{array}$ \\
\hline Pedro & $\begin{array}{l}\text { Éramos muito, muito, muito vigiados e tem mais, mesmo vigiados eles ainda pisavam na } \\
\text { bola, a gente fazia sacanagem. } \\
\text { Ah! A punição era vai pra dentro que a porrada vai comer, era de duas, de três palmadas, } \\
\text { quatro. } \\
\text { Quem batia eram as funcionárias, quando não os mais velhos, porque era assim, os mais } \\
\text { velhos cuidavam dos mais novos. }\end{array}$ \\
\hline
\end{tabular}

As narrativas indicam um investimento disciplinar no corpo infantil. A vigilância e a punição como mecanismos disciplinadores eram os recursos orientadores para manter a ordem e o funcionamento da instituição, bem como, as determinações de regras e tarefas a cumprir. Estes são os elementos constitutivos do funcionamento institucional.

O uso da palmatória como instrumento de correção transformou-se em uma prática cultural autorizada e de uso bastante comum na educação das crianças brasileiras. A opção em disciplinar pela dor, aponta para uma concepção eficaz do uso deste recurso punitivo-corretivo "[...] A palmatória representava um símbolo de poder, de hierarquia, de diferenças geracionais e de instrumento civilizatório [...] (ARAGÃO e FREITAS, 2012, p.26). Além do uso da palmatória, as narrativas indicam o uso de outros mecanismos de punição e controle das crianças, como ficar de joelho no milho, ficar de frente para parede, ficar sozinho em sala escura, ficar sem recreio e ser impedido de brincar.

Foucault (2013b) informa que o modelo de punição baseado no isolamento espacial do sujeito, como o descrito pelos ex-internos, em que se colocava a criança em uma sala escura, é inspirado nos costumes religiosos dos conventos, em que eram construídas celas para o exercício da solidão do corpo e da alma, como forma de ficar a sós com os seus erros e tentações. O Educandário como instituição administrada internamente pela congregação religiosa das filhas da caridade São Vicente de Paula, adotava essa tradição punitiva religiosa. As narrativas indicam que esse mecanismo punitivo 
corretivo era adotado conforme a gravidade da infração cometida. A sala escura era uma forma de exercer "[...] com o máximo de intensidade, um poder que não será abalado por nenhuma outra influência; a solidão é a condição primeira da submissão total [...]” (FOUCAULT, 2013b, p.223).

O controle sobre os sujeitos é um aspecto constitutivo das sociedades organizadas e, também, das instituições. E o controle social de crianças compõe essa forma de organização social, baseada no controle dos sujeitos, porém, as crianças, por serem dependentes dos adultos para o atendimento de suas necessidades de sobrevivência, acabam sendo envolvidas por uma relação de controle e poder de seus corpos e comportamentos pelos adultos, colocando-as numa posição desvantajosa, desigual e hierarquizada, em que esse controle e esse poder podem ser utilizados de forma exacerbada, em função da condição que é própria do ser criança - a dependência.

Sarmento (2005) lembra-nos que o poder de controle dos adultos sobre as crianças é reconhecido e exercido, colocando a infância numa posição subalterna na estrutura social. Essa afirmação reforça a importância do olhar para a infância e para a condição do ser criança dentro das estruturas sociais e, também, de olharmos para as relações que são estabelecidas entre crianças e adultos nos diferentes espaços institucionais. As narrativas reforçam a presença significativa do poder sobre o corpo infantil - marca histórica das relações adulto-criança, infância-sociedade, e, nos faz afirmar que este poder foi vivenciado com maior rigor e violência por crianças que viveram a história da infância em instituições.

Nas instituições voltadas à infância o poder sobre a criança corre o risco de ser exercido sem limites, ponderações e controle, podendo resultar em atos opostos à proteção e cuidados, como os castigos físicos e psicológicos vivenciados por algumas crianças do Educandário Eunice Weaver. Portanto, podemos afirmar que a condição e as especificidades do ser criança, aliada à construção social da infância e às concepções de criança na modernidade, suscitaram um investimento no corpo infantil, colocando a condição de ser criança como um sujeito passível ao governo e controle do outro, chegando a um poder exacerbado sobre as crianças que foi delegado à instituição.

Foucault (2013a) informa que as características das instituições para crianças situam-se no envolvimento com o controle e disciplinamento dos corpos, com o uso do espaço com caráter disciplinador, submetendo as crianças à opressão. Esse autor destaca que o exercício de poder foi racionalizado como a arte de governar, com técnicas de disciplinamento para educar o corpo. A disciplina é definida por este autor como uma técnica de poder que implica uma vigilância constante dos indivíduos, é uma maneira de gerir os homens. 
A disciplina é uma técnica de poder que implica uma vigilância perpétua e constante dos indivíduos. Não basta olhá-los às vezes ou ver se o que fizeram e conforme à regra. É preciso vigiá-los durante todo o tempo da atividade e submetê-los a uma perpétua pirâmide de olhares (FOUCAULT, 2013a, p.61).

Para esse autor, a disciplina é um poder contínuo que se exerce sobre o indivíduo, com registros, inspeções, revistas sobre o corpo individual, são fórmulas gerais de dominação, é um poder exercido sobre a singularidade do sujeito. A disciplina é empregada como forma de garantir a dominação sobre o outro e, nas crianças, esse emprego recebe um maior investimento, pois a ordem não necessita ser explicada, mas apenas promover o comportamento desejado. "[...] O treinamento dos escolares deve ser feito da mesma maneira: poucas palavras, nenhuma explicação [...]" (FOUCAULT, 2013b, p.160).

Esse autor também informa que a punição é um mecanismo que visa cumprir a obediência para o alcance da normalização. Uma das funções da punição é a prevenção, é o olhar para o futuro, punir para impedir a reincidência e, construir um comportamento de temor diante dos castigos, diminuindo dessa forma, o desejo de transgredir. As medidas punitivas não são para Foucault (2013b) mecanismos que são utilizados apenas para impedir, excluir, mas que também possuem efeitos úteis e positivos, pois mantém as suas funções.

A obrigação das crianças de cumprir com uma rotina de disciplina e vigilância diária era garantida pelo regulamento geral dos preventórios brasileiros que possuía um capítulo sobre a disciplina determinando nos seus artigos que:

Art.32 - A disciplina será exercida pelo corpo administrativo, com recurso para a direção geral, quando se tornar preciso, afim de serem aplicadas as penalidades máximas de dispensa, demissão ou expulsão conforme se trate de empregados, funcionários ou internados ${ }^{6}$.

Art.33 - Para auxiliar a manutenção da ordem e disciplina nas aulas, refeitórios, dormitórios e recreios, dentro de um regime de respeito e tolerância, serão criados os cargos de guardião para a seção masculina e guardiã para a seção feminina.

\footnotetext{
${ }^{6}$ Regulamento dos preventórios para filhos de lázaros instalados no Brasil.
} 
Conforme o regulamento, todos aqueles que compunham o conjunto de pessoas da instituição eram passíveis de sanções que poderiam chegar à expulsão da instituição. Porém, a preocupação em manter a ordem e a disciplina impunha um controle maior sobre as crianças, com a indicação da presença de pessoas destinadas a exercer a vigilância efetiva dos corpos infantis. Os ensinamentos da disciplina rígida, obediência e submissão constituíram a subjetividade das crianças institucionalizadas, pois grande parte dos internos adentraram o espaço institucional logo após o nascimento, sem terem tido a possibilidade de qualquer outro tipo de experiência socializadora.

\section{CONSIDERAÇÕES FINAIS}

As crianças do Educandário estavam situadas em um momento histórico em que eram compreendidas como o tudo e o nada. Um tempo de mudanças, tempo de ciência, tempo de adoção e implantação de políticas públicas que refletissem o esforço do país em se tonar uma nação civilizada. E foi nesse tempo e espaço, de novos ideários e modelos civilizacionais a serem seguidos, que o isolamento de doentes trouxe ao campo das políticas públicas brasileiras, nas primeiras décadas do século XX, propostas de renovação, desenvolvimento e progresso, baseadas na regeneração da raça. Nesse processo de mudanças, a preocupação com as crianças que não possuíam hanseníase ganhou dimensões e proporções médico-políticas tornando-as o tudo e o nada. O tudo, é constatado nos discursos políticos sobre a criança como futuro da nação, e nas prescrições de proteção e cuidado que envolviam a defesa do isolamento. E o nada, quando seu corpo foi visto como vulnerável ao contágio da doença e quando suas vivências na instituição foram atravessadas por violência física e psicológica, e, pelo exercício do controle e poder sobre os seus corpos de forma exacerbada.

Percebemos que as vivências de infância em dada sociedade são influenciadas pelos valores, pelos acontecimentos, pelo poder que emerge de grupos que determinam a organização social, que indicam os perigosos, os anormais, os que ameaçam a unidade, tendo que ser isolados para instaurar a normalidade. O isolamento institucional das crianças que viveram no Educandário Eunice Weaver, é resultado de uma sociedade que viveu um momento histórico em que a base biológica da existência orientou políticas que repercutiram na organização social, excluindo, banindo dos espaços de circulação social o corpo ameaçador. A criança foi percebida como pertencente biologicamente a uma linhagem negativa e, o isolamento e separação dos pais seria uma forma de superar aquilo que sua linhagem lhe legou. 
O trabalho como elemento constitutivo do projeto civilizador marcou a infância institucional, assim como, a disciplina e os castigos físicos, constituindo a história da infância das crianças do Educandário. Controle e dominação foram as forças orientadoras das experiências educativas das crianças que viveram no Educandário Eunice Weaver em Belém. Mais do que conhecimentos, se ensinou obediência, se ensinou comportamentos desejáveis. O controle esteve no centro das ações sobre a criança, o controle dos corpos, o controle da doença, o controle médico, o controle disciplinar, o controle dos comportamentos, o controle do contágio.

A história da infância e a história de crianças, ensina-nos a olharmos sobre o importante papel e poder atribuído na modernidade às instituições de educação de crianças, em que a educação pela imposição predominava em detrimento do diálogo. As crianças eram ensinadas desde cedo o que se esperava delas no futuro: a obedecer, a serem disciplinadas. As experiências educativas das crianças do Educandário foram ancoradas em práticas que privilegiaram o controle e o poder exacerbado sobre as crianças, secundarizando a importância fundamental dos vínculos afetivos e emocionais que envolve o trabalho com crianças. Por isso, destacamos sobre a importância do desenvolvimento de estudos históricos que visem o desocultamento das experiências institucionais de crianças no passado, para refletirmos sobre as relações e a realidade vivida pelas crianças ao longo de suas experiências educativas em instituições, revelando as consequências que, práticas ancoradas no controle e poder exacerbado, podem trazer para a vida de crianças.

\section{REFERÊNCIAS}

ARAGÃO, Milena; FREITAS, Anamaria G. Bueno de. Práticas de castigos escolares: enlaces históricos entre normas e cotidianos. Conjectura, v.17, n.2, p.17-36, maio/ago. 2012.

FOUCAULT, Michel. Microfísica do poder. Organização e tradução: Roberto Machado. Rio de Janeiro: Graal, $2013 a$.

FOUCAULT, Michel. Vigiar e Punir: Nascimento da prisão. Tradução: Raquel Ramalhete. 41.ed. Petrópolis, RJ: Vozes, 2013b.

GOUVEA, Maria C. Soares de. A escrita da história da infância: periodização e fontes. In: SARMENTO, Manuel; GOUVEA, Maria C. Soares de (Orgs). Estudos da Infância: Educação e Práticas Sociais. 2 ed. Petrópolis, RJ: Vozes, 2009.

HEYWOOD, Colin. Uma história da Infância: da Idade Média à época contemporânea no Ocidente. Trad. Roberto Cataldo Costa. Porto Alegre: Artmed, 2004.

Livro da Campanha da Solidariedade em Prol da Construcção do Preventório para filhos sadios dos lázaros, no Pará. Belém: Belém: Papelaria Loyola, 1939. Acervo do setor de obras raras da Biblioteca Arthur Viana 
PENNA, Belisário. O problema brasileiro da lepra. $1^{\text {a }}$ Conferência realizada na sessão de 22 de julho de 1926 da Academia Nacional de Medicina. Archivos Rio Grandenses de Medicina. V.08, n.02, fev.1929, p.05-16. Disponível em: http//www.seer.ufrgs.br. Acesso em: 13/11/2015.

Regulamento dos Preventórios para filhos de lázaros instalados no Brasil. Rio de Janeiro, 1941.Arquivo Gustavo Capanema; Série correspondências; GC 766f. CPDOC/FGV - Centro de pesquisa e documentação de história contemporânea do Brasil. Fundação Getúlio Vargas.

RIZZINI, Irene. O Século Perdido: raízes históricas das políticas públicas para a infância no Brasil. - 2 ed.rev.- São Paulo: Cortez, 2008.

SARMENTO, Manuel J. Crianças: educação, culturas e cidadania activa. Refletindo em torno de uma proposta de trabalho. Perspectiva, Florianópolis, V.23, n.01, p.17-40, jan/jul. $2005 . \quad$ Disponível em: http://www.ced.ufsc.br/nucleos/nup/perspectiva.html. Acesso em: 16/05/2016.

SOUZA ARAUJO. Heráclides C. História da Lepra no Brasil. Vol. II. Período Republicano (1889-1946). Álbum das organizações antileprosas. RJ: Imprensa Nacional, 1948.

SILVA, Jairo de Jesus Nascimento da. Em busca da Cura: a institucionalização da medicina acadêmica em Belém e sua relação com outras práticas terapêuticas entre 1889-1925. Tese (Doutorado em História Social). Universidade de São Paulo/USP, São Paulo, 2014.

STEARNS, Peter N. A Infância. Trad. Mirna Pinsky. São Paulo: Contexto, 2006. 


\section{INFÂNCIA E EXPERIÊNCIAS EDUCATIVAS NO EDUCANDÁRIO EUNICE WEAVER EM BELÉM/PARÁ (1942-} 1980)

RESUMO: Este artigo apresenta alguns resultados da pesquisa que investigou a infância e as experiências educativas de crianças que viveram no Educandário Eunice Weaver em Belém do Pará (1942-1980). O estudo teve como objetivo central explicitar a infância e as experiências educativas de crianças que foram afastadas dos pais e do convívio social para o controle e prevenção da hanseníase. Os procedimentos adotados foram a entrevista em história oral híbrida e temática e a pesquisa documental. Os resultados da pesquisa revelam uma história de crianças que foram retiradas do convívio com seus familiares e do convívio social, construindo assim uma forma de se vivenciar a infância baseada no isolamento, no controle dos corpos infantis por meio do disciplinamento e da violência física e psicológica.

Palavras-chave: História da Infância-Pará; Educandário Eunice Weaver; Experiências educativas de crianças.

\section{CHILDHOOD AND EDUCATIONAL EXPERIENCES AT EDUCANDÁRIO EUNICE WEAVER IN BELÉM/PARÁ} (1942-1980)

SUMMARY: This paper presents some results of the survey that investigated children and the educational experiences of children who lived in the Educandário Eunice Weaver in Belém do Pará (1942-1980). The study aimed to clarify central childhood and educational experiences of children who have been away from the parents and the social get-together for the control and prevention of leprosy. The procedures adopted were the interview in hybrid and thematic oral history and documentary research. The survey results reveal a story of children who have been removed from the living with their families and the social conviviality, building a way to experience childhood based on isolation, in control of the children's bodies through the discipline and the physical and psychological violence.

KEYWORDS: History of childhood-Pará; Educandário Eunice Weaver; Educational experiences of children.

INFANCIA Y EXPERIENCIAS EDUCATIVAS EN EL EDUCANDÁRIO EUNICE WEAVER EN BELÉM/PARÁ (19421980)

RESUMEN: Este trabajo presenta algunos resultados de la encuesta que investigaron los niños y las experiencias educativas de los niños que vivían en el Educandário Eunice Weaver en Belém do Pará (1942-1980). El estudio pretende clarificar central infancia y experiencias educativas de los niños que han estado lejos de los padres y la reunión social para el control y la prevención de la lepra. Los procedimientos adoptados fueron la entrevista en híbridos y la historia oral temática y de la investigación documental. Resultados de la Encuesta revelan una historia de niños que se han quitado de los vivos con sus familias y la convivencia social, construyendo una forma de experimentar la niñez basada en aislamiento, en el control de los cuerpos de los niños a través de la disciplina y la violencia física y psicológica.

PALABRAS CLAVE: Historia de la infancia-Pará; Educandário Eunice Weaver; Experiencias educativas de los niños. 